\title{
Cultivation of Chinemys Reevesii (Chinese Three Keeled Turtle) in Greenhouse System
}

\author{
PHYO SANDI ${ }^{1,4}$, YELIN JIANG ${ }^{1,2,3}$, YUNSHENG CEHNG ${ }^{1,2,3}$, FEN WANG ${ }^{2,3}$, WANG JIAJIA ${ }^{1,2,3}$ and Zhang Tai Xiang ${ }^{5}$ \\ ${ }^{1}$ Fishery Institute, AnHui Academy of Agricultural Science, HeFei, AnHui, China \\ ${ }^{2}$ Anhui Engineering Research Center for turtle Farming Technology, HeFei, AnHui, China \\ ${ }^{3}$ Fisheries Academician Workstation of Anhui Academy of Agricultural Sciences, HeFei, AnHui, China \\ ${ }^{4}$ Biotechnology Research Departments, Ministry of Education, Myanmar \\ 5Zhonghe Zhenxin special Aquaculture Cooperative, JinAn District, Lu'an, AnHui, China
}

*Corresponding Author: Yelin Jiang, Fishery Institute, AnHui Academy of Agricultural Science, HeFei, AnHui, China, Phone: 86-13866171303; Email: jiangyelin@qq.com

Received: February 05, 2020; Accepted: February 24, 2020; Published: March 03, 2020;

\begin{abstract}
Chinemys reevesii (Chinese three keeled turtle) is developed in china's turtle farms for production in pet trade market and chinese medicine. The aim of this study was to calculate growth rate and survival rate of juvenile $C$. reevesii under the greenhouse based overwinter breeding technology to survive and not to get weight loss. 2000 stocking density were cultured in each twenty tank and then randomly collected 10 turtles from each tank during January to may 2019 to calculate growth rate. The results showed that the temperature was maintained within the range of $30 \pm 2^{\circ} \mathrm{C}$ and ambient air was controlled by $32 \pm 2^{\circ} \mathrm{C}$. After five months cultivation, final weight reached average $278.44 \pm 57.61 \mathrm{~g}$ with $125.13 \pm 99.73$ final weight gain by high survival rate of $89.8 \pm 2.73 \%$ and low feed conversion rate $1.8 \pm 0.2$. Moreover, resulting dissolved oxygen 3.8 to $9 \mathrm{mg} / 1$, $\mathrm{pH}$ between 7 to 8 , ammonia and nitrite at 0.005 to $0.02 \mathrm{mg} / \mathrm{l}$ showed suitability of this species cultivation. As a result, this study will be hopeful artificial husbandry to increase healthy growth rate during overwintering turtle in greenhouse system.
\end{abstract}

Keywords: chinese three keeled turtle; greenhouse; growth rate; survival rate, FCR, temperature, water quality

\section{Introduction}

For many centuries, turtles have been used as food, pets and in traditional medicine in different regions of the world [1]. Freshwater turtles are being developed for traditional medicine, meat, eggs and pet trade. Because of this, turtle farmings are boomed in aquaculture industries in the past two decades [2]. As farm bred turtles took advantage of good numbers in the last 20 years, the market share has raised significantly. Asia especially china is stood at the top of world turtle consumption as food and medicine. Despite having used in turtle products for thousands of years, turtles command a high price and this is the reason to develop farms in china [2]. To organize large scale commercial turtle farms some companies have invested larged sums of money. Although early efforts focused almost exclusively on the Chinese soft shell Pelodiscus sinensis [1], the farm output of this species has now satiated demand. Thus, farms have started to rear more valuable hard shelled turtles.

Chinemys reevesii, Reeve turtle (or Chinese three keeled turtle) (family Geoemydide) is widely distributed in eastern asia, including Central and Eastern contenital china, Taiwan, Kimmen island, Southern and central japan and korea [3] This species is one of the most commercially important turtles for aquaculture and is widely cultured in China $[4,5]$. Shell from C.reevesii are the most valuable in the high volume Traditional Chinese Medicine market in Taiwan [1]. In china, especially Anhui provience, the estimate production rate is flucturated from 2012 to 2018 . More than $80 \%$ of this species occur in china [6]. This species has been classified as endangered in the IUCN Red List of Threatened species [1, 6] and Chinese Red List of Threatened species [7] owing to overhunting and habitat destruction in the wild.

As turtle are reptiles, hard shell turtles cannot control their internal body temperature so that they are greatly affected by temperature. The best way for warming themselves is to move to be warmer place during the winter. In central china such as Anhui Province, hard shell turtle usually hatches during June to September and juveniles are too weak to grow through winter time. Most hard shell turtle farmers always use greenhouse system to hibernate for them during winter and for early start up. In the low range of temperature, they can get weight loss. In the greenhouse, air and water temperature are needed to control constantly between 30 and $32^{\circ} \mathrm{C}$ ( $\mathrm{Li}$ et al, 2009). There are many kind of greenhouse designs in markets so that farm owners can choice as they like. Turtles can adapt to natural or artificial environments well, but in greenhouse, turtles, when reared in high density and poor environment are prone to disease. To minimize such occurrences, culture techniques and several culture models, have been developed and introduced as standard processes for turtle culture. Hence, the main objective of this paper was threefolds (1) to utilize greenhouse based breeding program (2) to use effective microbe in monitoring water quality under greenhouse (3) to develope economic 
model of hard shell turtle by describing weight increment for current and future turtle farming. This study will be able to get advantages to reduce farmers hesitate using greenhouse.

\section{Materials and Methods}

Experimental Culture Site, Greenhouse Design and Construction: The green house was located in Luan city in western Anhui Province. Its administrative area spans 313002.15 N Latitude and 1163606.35 E Longitude. Luan has a monsoon influenced, humid subtropical climate. Winter are cold and damp, the January 24 hours average temperature is $2.6 \mathrm{C}(36.7 \mathrm{~F})$. Summer is typically hot and humid, with a July average of $27.8^{\circ} \mathrm{C}\left(82.0^{\circ} \mathrm{F}\right)$. Because of long time low temperature conditions, it was not suitable for the growth of juveniles three keeled turtle and could hardly survive. In this study, the cultivation period in greenhouse was 150 days from January 2019 to may 2019.

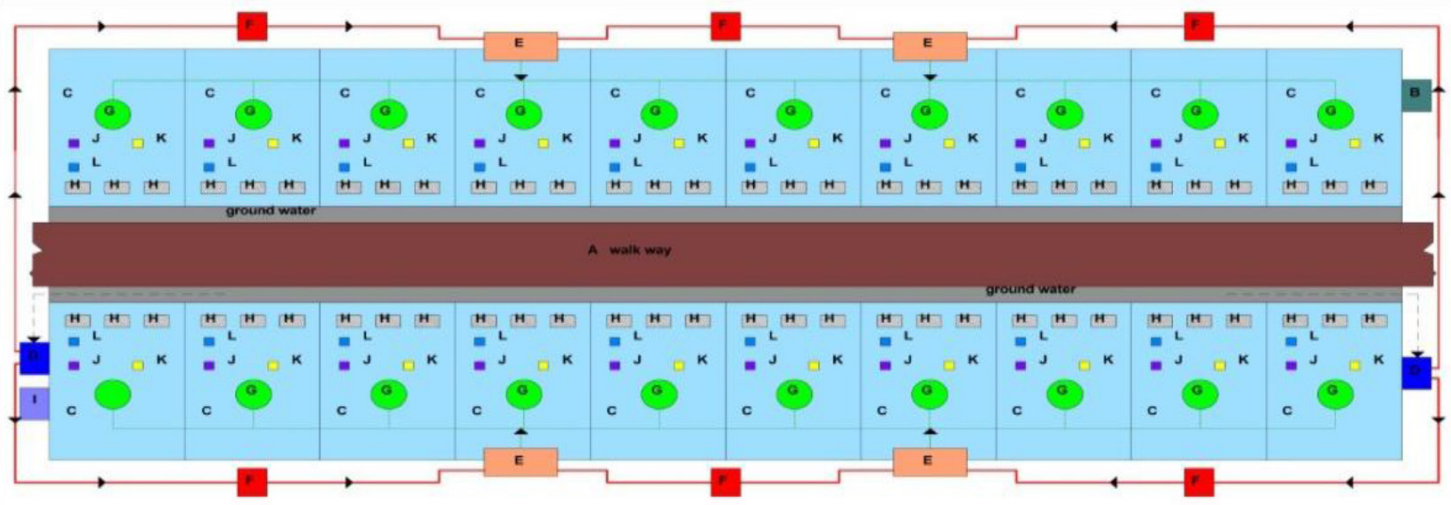

$\begin{array}{ll}\text { A. Walk Way } & \text { G. Water outlet from heater water tank } \\ \text { B. Three blade roots blower } & \text { H. Shelter } \\ \text { C. Culture tank } & \text { I. Fan } \\ \text { D. Water pump } & \text { J. Aeration } \\ \text { E. Heater water tank } & \text { K. Lamp } \\ \text { F. Water inlet from ground water } & \text { L. Under water feeding platform }\end{array}$

Figure 1: Plan view of greenhouse.
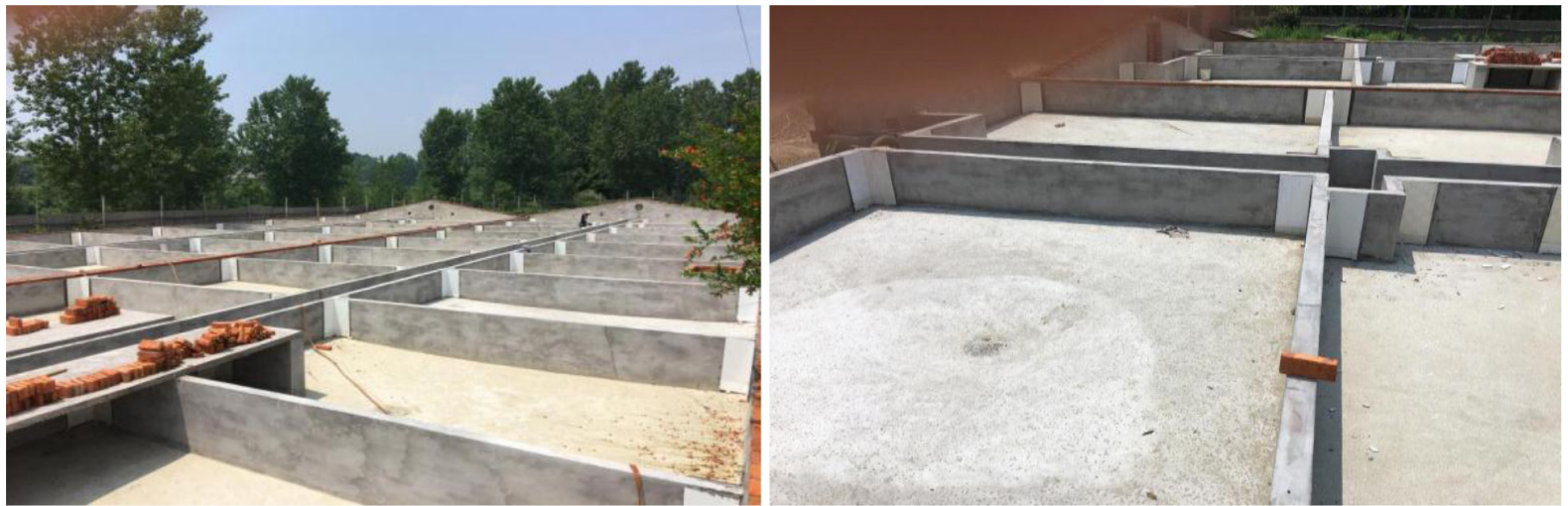

Figure 2: Construction of Greenhouse in Luan city in western Anhui Province, China.
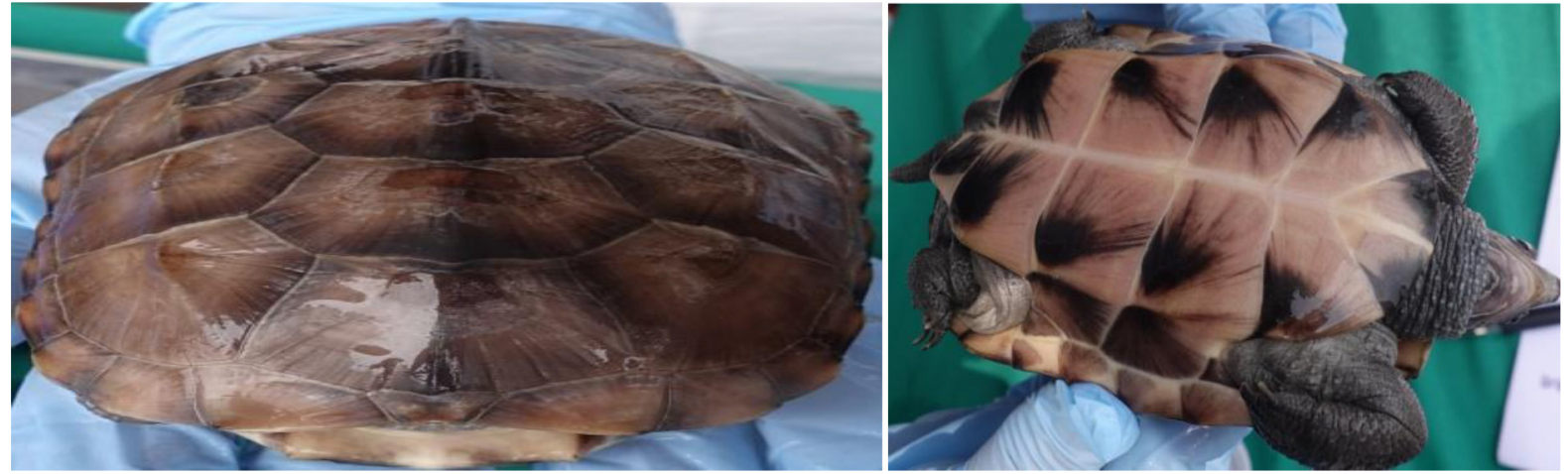

Figure 3: Juvenile Chinemys reevesii. 
The greenhouse design of chinemys reevesii were considered for the suitability of its behavior and physiological parameters and effects on the external environment and construction cost. Its design for juvenile chinemys reevesii were (1) to gain healthy turtles with good weight gain, (2) to control for a suitable and healthy culture environment, such as optimal air and water temperature and good water quality, (3) use of effective microbes to reach high productivity.

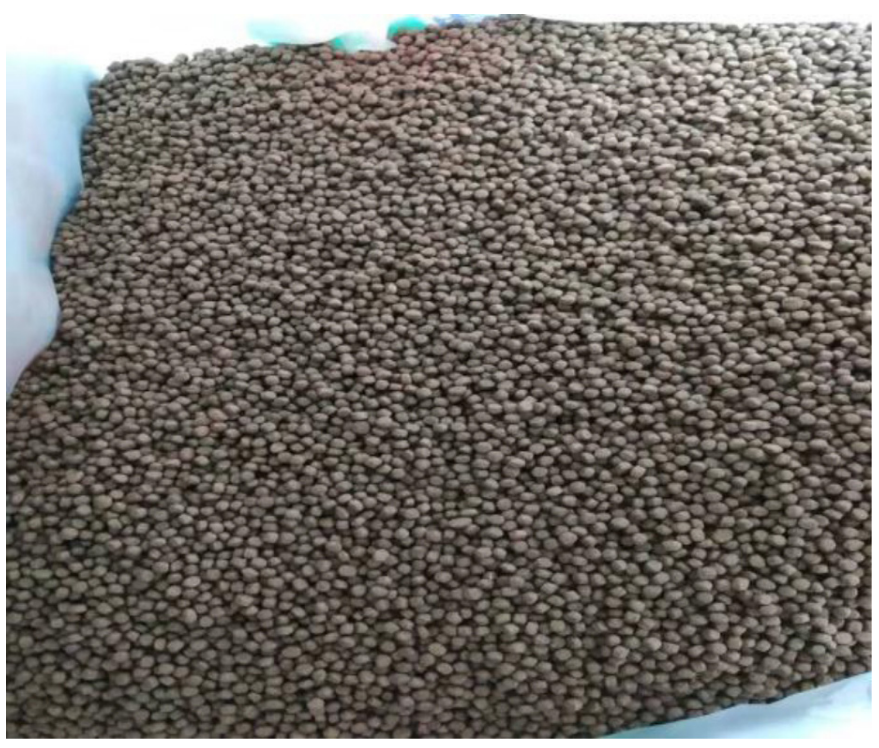

Figure 4: Juvenile turtle pellet.

The cardinal whole factory was $1130 \mathrm{~m}^{2}$ and made rooms for two greenhouses, two hatching rooms, one storage rooms and the other facilities such as oxygen supply equipment, four oxygen generators, pipeline oxygen supply and drainage facilities. Each greenhouse has twently $14.17 \mathrm{~m}^{2}$ culture tanks. All tanks were made of concrete brick. For each culture tank, there were included shelter, underwater feeding platform, water inlet and outlet drainage system, temperature control system. As turtle are timid animal and hide behind shelters without feeding, they need shelters to take a rest, activity, hidden from noise and sudden circumstance. Those shelters, $1.2 \mathrm{~m}$ squared polyethylene knotless small mesh $(0.5 \mathrm{~cm}$ square) were parallel with a distance about $80 \mathrm{~cm}$ to each other at the depth of $30 \mathrm{~cm}$ water. For feeding, feeding platform were used in each culture tank. Each asbestos platforms (100 x $120 \mathrm{~cm}$ ) was places under water with $40 \mathrm{~cm}$ depth. There were foam insulation cotton on the roof. Total project budget for one greenhouse were about 130,000 RMB (approximately 18571 USD). Construction began in March 2016 and was completed by May 2016.

Aeration system, water supply and discharge system: In the greenhouse, a three blade roots blower $(2.2 \mathrm{kw})$ was used for aeration system. When the compressed air was turned on, an upwelling flow with microbubbles was generated. Nine air stones for each culture tank were aerated constantly.

Two $4 \mathrm{~mL} \times 0.62 \mathrm{mH} \times 1.3 \mathrm{~m}$ W heater water tanks was filled from the ground water with water pump. These tanks ran to culture tanks with water outlet pipe line system. Two $4 \mathrm{~cm}$ diameter water supply inlets were set through the tank wall to adjust water level through valves. Chinese three keeled turtle are not good swimmer so that the water depth should be kept relatively shallow [8]. The reason to keep shallow water was that it was easy to swim and reduce energy and also save production cost. Moreover, according to the turtle respiration system, they have to come water surface to breath air for a while. Therefore, water level was controlled at $0.8 \mathrm{~m}$.

For discharge system, the tank bottom was built in the form of wok shaped sloping toward the central drain. The bottom type drainage caliber of greenhouse culture tank was $40 \mathrm{~cm}$ width. As uneaten feed and fees settled down at the bottom as the organic debis, they can easily siphoned to the seawage ponds for filtration system. Each culture tank had their own discharge system because their own discharge system can prevent the cross contamination and infection. Water was drained one tenth of the amount of water in each culture tank once a week. The underground $5 \mathrm{~cm}$ diameter pipe was connected to $\mathrm{L}$ standing pipe outside the culture tank.

Temperature control system: The framework pipes was made up of stainless steel to support the arc shaped ceiling. The framework was so strong that this can not only withstand snow falling in winter but also light insulation. There was sharp slope on both sides of the roof not to stay snow and to fall off. The highest point of the celling was $1.8 \mathrm{~m}$. Welling and ceiling were built with thermal insulation layers.

As with temperate species, Chinese three keeled turtles are absolutely affetcted by temperature. The only recourse they have for warming themselves is to remove warmer place for winter period. Temperature gradients should be provided for the water, ambient air and basking area $[9,10]$. To provide a warm environment in turtle greenhouse, air need to heat first and secondly water is warmed through air to water heat transduction and aeration. Firstly water heating system may cause evaporation and inside greenhouse foggy and poor visibility. Moreover, moist air can be a favour to grow pathogenic microbes. Water should be maintained within the range of 30 to $32^{\circ} \mathrm{C}$, the ambient air between $32-34^{\circ} \mathrm{C}$. A basking area where the turtle can leave the water completely, with a good basking light to help the turtle thermo regulate, is an absolute must. A good heat emitting light should always be provided over the basking area. For basking area there were four 32 Watt in each culture tank.

Stocking: The culture tanks had size $420 \mathrm{~cm} \mathrm{x} 600 \mathrm{~cm} \mathrm{x} 68 \mathrm{~cm}$ and water level was $0.8 \mathrm{~m}$ depth as the water depth should never be less than about 1.5 times the length of the turtle shell. Before, transferring the turtle into the culture tank, they are needed to disinfect with calcium oxide solution at $50-100 \mathrm{mgl}^{-1}$ for 3-5 days. Stocking density in the culture tank was 2000 turtles $\mathrm{m}^{-2}$. The average weight of the turtles were $123.68 \mathrm{~g}$.

Useage of effective microbe: Effective microbe, Lactobacillus acidophilus and Candida prion producing strain were used. The effectiveness of this product can proliferate beneficial intestinal flora, control the harmful bacteria to the intestine, stomach, and pancreas of the hard shell turtle, so as to achieve the purpose of producing bacteria by bacteria reduce the occurrence of disease $[11,12]$. The beneficial compound bacteria contained in this product can attach to animal feces, decompose the excreted feces twice reduce the pollution of feces to water body from the source, control the function of sticking, heat, eutrophication of water body and harmful algae breeding. Aquatic 
feed is a high protein and nutrient substances so that long term stacking will breed and contaminate will breed and contaminate with a set of bacteria [13]. This product has the function of keeping fresh preventing feed mildew and removing the clamor for mildewed feed.

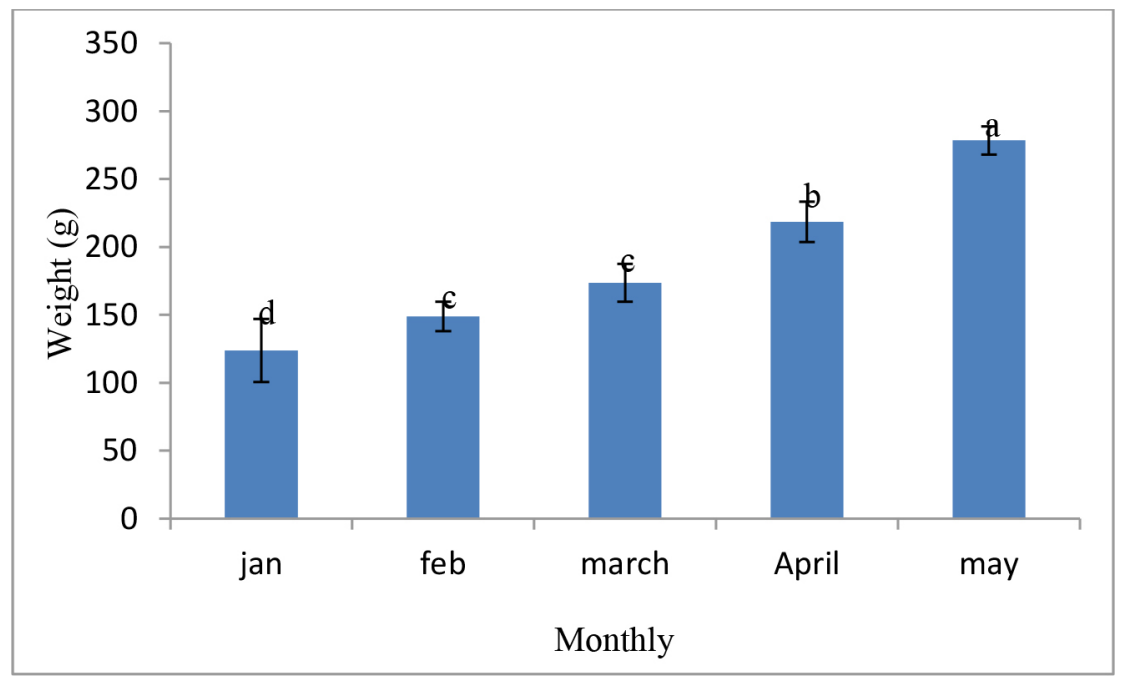

Figure 5: Expression of weight increment of juvenile chinemys reevesii. Bar indicate the standard error of the mean $(\mathrm{n}=30)$. Different Latin letters on top of the columns denote statistically significant differences $(\mathrm{P}<0.05)$.

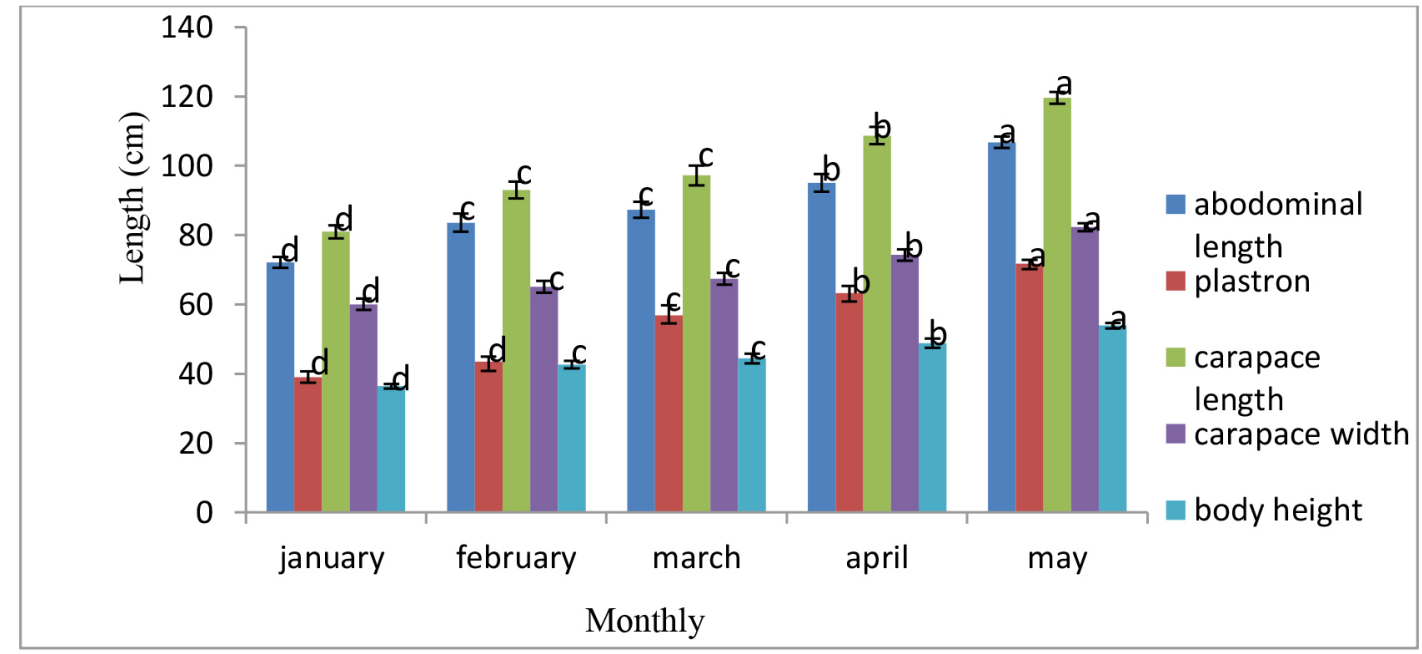

Figure 5: Expression of length increment of juvenile chinemys reevesii. Bar indicate the standard error of the mean $(\mathrm{n}=30)$. Different Latin letters on top of the columns denote statistically significant differences $(\mathrm{P}<0.05)$.

Water management: Although the uneaten feed less and feces waste from culture tanks were routinely drained out to the settling tank, the dissolved organics from the waste can still remain and accumulate in the culture tank [12]. It will be able to become favourable for microbe propagation. Because of this, the water quality will be declined. This situation was especially evidenced in intensive type of aquaculture [14]. It was reported that bacteria can get rid of pollutants by digesting them [15]. EM sprayed to culture water body at the concentration of $5 \mathrm{gm}$-3culture water once a month in the first 3 months and 10 gm- 3 of culture water at fortnightly. Water was collected monthly around 10:00 Am for each pond and water temperature, $\mathrm{PH}$, dissolved oxygen, ammonia and nitrite were analyzed by standard methods using spectrophotometer.
Feeding: Reeve turtle are omnivores and there is a wide variety of commercial turtle food available on the market and most have been formulated to provide optimum nutrition for aquatic turtles at all stage of growth. Juvenile hard shell turtles were fed juvenile feed from Fujian Zheng Yuan Feed Co, Ltd. Feeding time was at 7:00 Am and at 18:00 Pm per days for winter. In this experiment, starting weight for turtles was average 123.68g. Breeding density was 2000 turtles per pond. The proximate chemical composition of turtle feed was moisture $\prec 10 \%$, crude protein $\geq 42 \%$, crude fat $\geq 5 \%$, crude fiber $\geq 5.0 \%$, crude ash $\leq 16.0 \%$,lysine $\geq 2 \%$, Calcium $\leq 4.5 \%$, total phosphous $\geq 1.2 \%$ and water $\leq 11.0 \%$. We added vitamin $\mathrm{C}$ for extra immunity protection. The maximum amount of feed per day have been $40 \mathrm{~kg}$. 
Moreover, Effective Microbes (EM) was fed when it first came out of shell. According to the manufacturer's specifications, Lactobacillus acidophilus, the main microbe in its EM, could secret acidolin, acidophilin and aetocidon and enhanced antagonistic function against entire pathogens in the intestine and to improve the immunity. EM needs $1000 \mathrm{~g}$ for the whole greenhouse. It was fed every half month.

Total ratio of feed rate was about $3 \%$ body weight at the first month and then altered monthly because this ration was determined monthly observations and experiment. If the uneaten feed was left, it was cleaned through the central drain.

\section{Result}

Survival and Growth rate: The juvenile initial weight was mean $123.68 \pm \mathrm{g}$ and final at $278.44 \pm 57.61 \mathrm{~g}$. The final survival rate got $89.8 \pm 2.73 \%$ after five months period. Furthermore, no bite mark, no bleeding, no pathogen had been checked. It was shown that this stocking density, 2000 turtle/tank was suitable for this period. Temperature is the major environmental factor for survival and growth weight.

Feed and feeding: In aquaculture, one of an important parameter was Feed Conversion Ratio (FCR) because upto about $60 \%$ of the total production cost was represented by feed cost. The lower the feed conversion ratio, the higher the economic return. Feed conversion ratio in this trail was $1.8 \pm 0.2 \mathrm{SD}$ (Table 1 ). The suitable nutrition and crude protein contant $42 \%$ became the good diet. In this trail, turtle was already finished within one hour after observation. Moreover, the usage of solid underwater feeding platform gave the favorite feeding site of juvenile turtle.

Table 1: Survival Rate and Growth Rate of juvenile C.reevesii.

\begin{tabular}{|l|c|c|c|c|c|}
\hline & $\begin{array}{c}\text { Final } \\
\text { weight }\end{array}$ & $\begin{array}{c}\text { Final } \\
\text { survival } \\
\text { number }\end{array}$ & $\begin{array}{c}\text { Survival } \\
\text { Rate }\end{array}$ & $\begin{array}{c}\text { Weight } \\
\text { Gain }\end{array}$ & FCR \\
\hline Mean & 278.44 & 1796 & 89.8 & 125.13 & 1.8 \\
\hline $\begin{array}{l}\text { Standard } \\
\text { deviation }\end{array}$ & 57.61 & 82.26 & 2.73 & 99.73 & 0.2 \\
\hline
\end{tabular}

Water quality: Every tank was tested water monitoring system. Changes of the monthly average temperature, ammonia, nitrite and dissolved oxygen in culture tanks from January 2019 to may 2019 are shown in Figures $(6,7 \& 8)$. All water quality parameter was met well water quality standard for fisheries (people republic of china national standard GB 11607-89). Water temperature was maintained within the range of $30 \pm 2^{\circ} \mathrm{C}$ which was the most favourable temperature for juvenile turtle's intake and growth. Geothermal heat pump system effectively controlled the narrow variation of temperature balance.

The monthly ammonia and nitrite were in the range of 0.005 to $0.02 \mathrm{mg} / \mathrm{l}$. In this experiment, good water quality could maintain by two factors. Firstly, routinely discharge of organic debris by central drainage greatly reduced the loading in the culture tank. Second, the use of EM may facilitate the assimilation of ammonia into microbe and reduced ammonia [12]. The dissolved oxygen level was maintained 3.8 to $9 \mathrm{mg} / \mathrm{l}$ and $\mathrm{pH}$ between 7 to 8 .

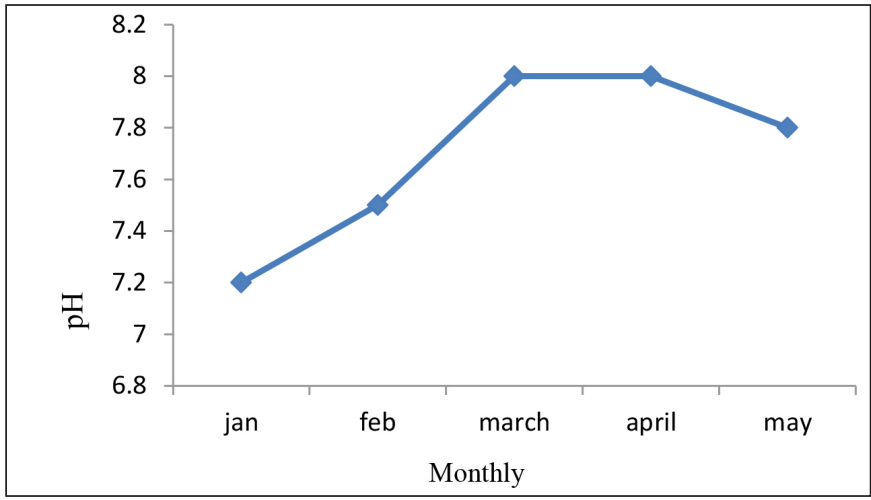

Figure 6: Average monthly $\mathrm{pH}$ of greenhouse culture pond from january to may.

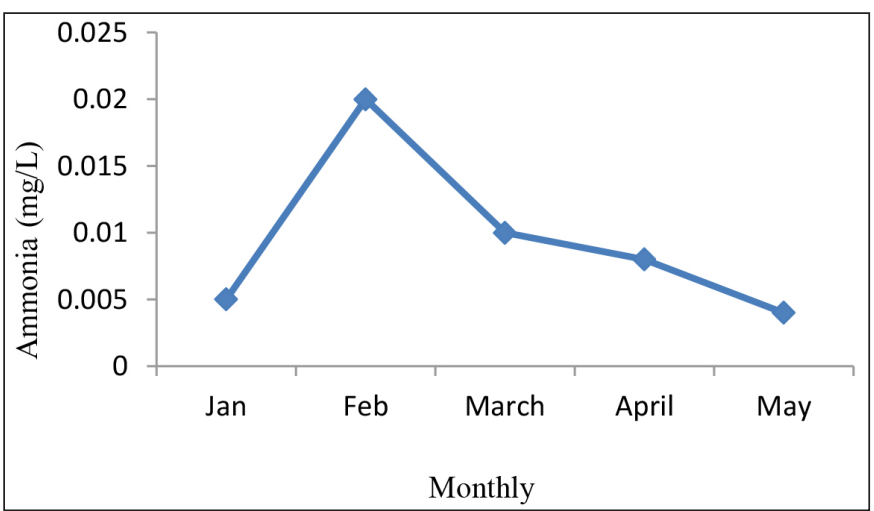

Figure 7: Average monthly Ammonia of greenhouse culture pond from january to may.

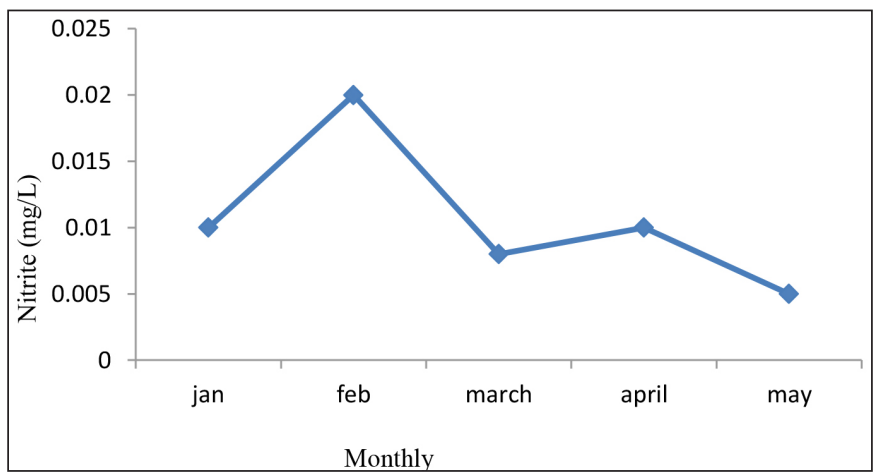

Figure 8: Average monthly Nitrite of greenhouse culture pond from january to may.

Ecological analysis: The cost of one greenhouse was 130,000RMB including slope shape greenhouse frame and plastic cover, twenty culture tanks and basic equipments. Electric fee was about 3369.63 $\mathrm{RMB}$ per month for one greenhouse. Labor cost was on the basis of $1500 \mathrm{RMB}$ per one month and the feed cost was $13320 \mathrm{RMB}$ per month. Benefit of production rate was 7500 RMB per ton.

\section{Discussion}

The cultivation of juvenile Chinese threekeeled turtle in greenhouse with suitable environment was important in green aquaculture system because this species was endangered species according to IUCN red list and also stood highly in medicine and pet trade market. Moreover, turtle cultivation in greenhouse were caused high mortality and not suitable for environment. In this paper, by using green house 
can show that there was no serious disease and pathogen event when checking any turtle health. Furthermore, the green house was designed to provide suitable and stable living environment [16]. The water temperature was steady under the control of ground source heat pump system. Stocking density influences survival, growth, health and feeding. Thus determination of stocking density for cultured animals is essential for optimizing production, profitability and sustainability. Hard shell turtle can fight and bite each other for food and space when getting high stocking density [17-29]. Generally, high stocking density can get high production rate but it will not always be true for economic benefit. In this study, the whole period survival rate and final stocking density number were $89.8 \pm 2.2 \%$ and $1796 \pm 84.23 \%$ respectively (Table 1). After monthly checking these species, no disease, no bite each other and no destructive each other were shown that this stocking density and culture tanks' capacity gave safety production. The reason for high increasing nitrite and ammonia concentration was due to high stocking density with dead turtle, feed residue and feces. But this study demonstrated that water quality of ammonia and nitrite was safe range because of good stocking density, usage of EM microbe and wok shaped tanked bottom design during this five month period. As shown in table 1, FCR $1.8 \pm \mathbf{0 . 2} \mathrm{SD}$ and protein content $\mathbf{4 2} \%$ was also favourable because this study used underwater feeding platform so that it can easily calculate feed conversion ratio after checking and calculating.. The ammonia and nitrite were in the safe range because the usage of EM. It was shown that water quality environment was suitable for the growth of juvenile turtle. The final weight, survival rate and FCR were also favourable after checking and calculating during these five months period.

\section{Conclusion}

This study could report that the greenhouse cultivation was more suitable than outer pond in winter period. Because of shelter, it can reduce the fighting and mortality so that it can get high survival rate. Moreover, underwater feeding platform system gave good feed and feeding facilities. Furthermore, the wok shaped tank bottom design was effective in great drainage system and maintained water to be cleaned. Usage of effective microbes could provide not only water quality but also feed rate. High survival rate $898 \pm 2.73 \%$, good feed conversion ratio $1.8 \pm 0.2 \%$, good water quality was concluded that it was excellent business by cultivation of juvenile turtle in greenhouse during over winter period. Moreover, the future of turtle farming is not only important for the economy of the region but also has potential to serve as the foundation for conservation and recovery of wild turtle population.

\section{Acknowledgements}

We wish to thank to Talented Young Science Program for one year period to do research work in china and Professor Jiang Ye Lin, fisheries institute, Anhui Academy of Agricultural Science, Hefei, Anhui Province. Special thanks go to Zhang Tai Xiang, the owners of the hard shell Turtle Farm who were welcoming to our research ideas and provided an overview of the past and current turtle market situation.

\section{Reference}

1. Chen T-H, Chang H-C, Kue K-Y 2009. Unregulated trade in turtle shells for Chinese traditional medicine in East and Southeast Asia: the case of Taiwan. Chelonian Conservation and Biology 8: 11-18.

2. Gong SP, Chow AT, Fong JJ, Shi HT (2009) The chelonian trade in the largest pet market in china: scale, scope and impact on turtle conservation. Oryx 43: 213-216.

3. Lovich JE, Ernst CH. In press. Maurem, Gotte, SW (1985) Geographic variation in the Asiatic turtle Chinemys reevesii (Gray) and the status of Geoclemys grangeri Schmidt. Journal of Herpetology 19: 238-245.

4. Aoki R (1974) On the imported individuals of Chinemys reevesii. Herpetile Notes 12: $122-124$.

5. DuW-G, SHEN J-W (2007) Growth and sexual size dimorphism in the Chinese three keeled pond turtle ( Chinemys reevesii). Acta Herpetologica Sinica 11: 42-47.

6. Hilton-Taylor C (2000) IUCN Red List of Threatened Species. Gland and Cambridage: IUCN.

7. Li Y, Li D (1998) The dynamics of trade in live wildlife across the Guangxi border between China and Vietnam during 1993 -1996 and its control strategies. Biodiversity and Conservation 7: 1-20.

8. Jiang YL (2016) Shelter for use in soft shelled turtle culture and its production method. Chinese Patent 201,610,485,845.3 Sep 2016 (in Chinese).

9. Du W-G, ZHENG R-Q, SHU L (2006) The influence of incubation temperature on morphology, locomotor performance, and cold tolerance of hatchling Chinese three keeled pond turtles, Chinemys reevesii, Chelonian Conservation and Biology 5: 294-299.

10. Zhang YP, Du WG, Shen JW, Shu L (2009) Low optimal temperature for food conversion and growth in the big headed turtle, Platysternon megacephalum. Aquaculture 295: 106-109.

11. Lei G,Yaohong Z (2010) Effect of Bacillus subtilis on growth performance , digestive enzyme activities and blood biochemical indices of Pelodiscus sinensis. Chinese J. Anim. Nutr 1: 42.

12. Lananan F, Abdul Hamid SH, Sakinah Din WN, Ali N, Khatoon H, Jusoh A, et al (2014) Symbiotic bioremediation of aquaculture wastewater in reducing ammonia and phouphorus utilizing Effective Microorganism (EM -1) and microalgae ( Chlorella sp.) Int Biodeter Biodegr 95: 127-134.

13. Hirai T (2003) Reeve's pond turtle, Chinemys reevesii, eaten by exotic bullfrog, Rana catesbeiana. Bulletin of Kansai Organization for Nature Conservation 25: 3-5.

14. Sharrer MJ, Summerfelt ST (2007) Ozonation followed by ultraviolet irradiation provides effective bacteria inactivation in a freshwater recirculating system. Aquac Eng 37: 180-191.

15. Rashed EM, Massoud M (2015) The effect of Effective Microorganisms (EM) on EBPR in modified contact stabilization system. Housing and Building National Research Center 11: 384-392.

16. Ji SC, Chen DG, Xiang SD, Lai NY (2003) Research application of terrapin greenhouse heating system based on ground source heat pump technology, Journal of Anhui Agri SCI 41: 13423-13425 (in Chinese).

17. Shi H, Fan Z, Yin F, Yuan Z (2004) New data on the trade and capative breeding of turtles in Guangxi Province, South China. Asiatic Herpetological Research 10: 126-128.

18. Chow M-C (1955) Notes on the remains of Chinemys from Hsiatsaohwan, Shihhung, northern Anhui. Acta Palaeontologica Sinica 3: 69-72.

19. Ewert MA, Jackson DR, Nelson CE (1994) Patterns of temperature -dependent sex determination in turtles. J Exp Zool 270: 3-15.

20. Fukada H, Ishihhara S (1974) Overwintering of hatchling of the turtle Chinemys reevesii, Japanese Journal of Herpetology 5: 45-48.

21. Galgon F, Fritz U (2002) Capative bred hybrid between Chinemys reevesii (Gay, 1931) and Cuora amboinensis kamaroma Rummler \& Fritz, 1991. Herpetozoa 15: $137-148$.

22. Haramura T, Yamange M, Mori A (2010) Radiotelemetric study of movement patterns of lotic freshwater turtles during breeding and hibernation seasons, Journal of Freshwater Ecology 25:251-259.

23. Iverson JB (1992) A Revised Checklist with Distribution Maps of the Turtles of the World. Richmond, Indiana: Privately printed 363.

24. Jiang YL (2012) Feeding platform in soft shell turtle culture pond. Chinese patent 201, 220215, 224.0 Dec 2012 (in Chinese).

25. Klemens MW (2000) Turtle Conservation. Washington, DC: Smithsonian Institution Press.

26. LEE JC-I, TSAI L-C, LIAO S-P, linacre A, Hsieh H-M (2009) Species identification using the cytochrome b gene of commercial turtle shells. Forensic Science International: Genetics 3:67-73. 
Yelin Jiang (2020) Cultivation of Chinemys Reevesii (Chinese Three Keeled Turtle) in Greenhouse System

27. Mc Arthur S, Wilkinson R, Meyer J (2008) Editors. Medicine and Surgery of Tortoises and Turtles. Oxford, UK, Wiley-Blackwell 600.

28. Stevens CE, Hume ID (1998) Contributions of microbes in vertebrate gastrointestinal tract to production and conservation of nutrients. Physiol. Rev 78: 393-427.
29. Zhou X, Niu C, Sun R, Li Q (2002) The effect of vitamin C on the non-specific immune response of juvenile soft shelled turtle (Trionyx sinensis). Biochem. Phys. A 131: 917-922. [Crossref]

\section{Citation:}

Phyo Sandi, Yelin Jiang, Yunsheng Cehng, Fen Wang, Wang Jiajia and Zhang Tai Xiang (2020) Cultivation of Chinemys Reevesii (Chinese Three Keeled Turtle) in Greenhouse System. Aquac Fish Stud Volume 2(1): 1-7. 